\title{
Development and validation of 3 Tesla functional cardiac magnetic resonance imaging in preterm and term newborns
}

\author{
Alan Groves*1, Gaia Chiesa1, Giuliana Durighel ${ }^{1}$, Stephen Goldring1, \\ Julie Fitzpatrick ${ }^{1}$, Sergio Uribe ${ }^{2}$, Reza Razavi ${ }^{2}$, Jo Hajnal ${ }^{1}$ and David Edwards ${ }^{1}$
}

Address: ${ }^{1}$ Imperial College London, London, UK and ${ }^{2}$ King's College London, London, UK

* Corresponding author

from 13th Annual SCMR Scientific Sessions

Phoenix, AZ, USA. 21-24 January 2010

Published: 21 January 2010

Journal of Cardiovascular Magnetic Resonance 20 I0, I2(Suppl I):O32 doi:I0.1 I86/I532-429X-I2-SI-O32

This abstract is available from: http://jcmr-online.com/content/I2/SI/O32

(c) 2010 Alan et al; licensee BioMed Central Ltd.

\section{Introduction}

Circulatory failure causes significant mortality and morbidity in newborn infants. Improvements in clinical circulatory care are limited by the paucity of accurate biomarker outcome measures for clinical trials.

\section{Purpose}

To develop and validate cardiac magnetic resonance (CMR) imaging techniques to assess ventricular function and systemic perfusion in preterm and term newborns, and to compare techniques to existing echocardiographic methods.

\section{Methods}

All scans were performed with a Philips 3-Tesla MR scanner. Infants were fed and allowed to fall into natural sleep without the use of sedation or anesthesia. Infants were laid in a custom made cradle, with ear protection and routine monitoring. A Flex-M surface receiver coil was placed on the chest wall. No respiratory compensation techniques were used. Acquisition parameters for phase contrast (PC) and balanced fast field echo (bFFE) imaging were optimised. PC assessments of flow were performed immediately distal to the aortic and pulmonary valves, as well as in the superior vena cava (SVC) and descending aorta (DAo). External validation of phase contrast measures was performed with a flow phantom. bFFE sequences were applied for 2 chamber, 4 chamber and short axis views. A short axis stack of 5-7 slices covered the left ventricle from base to apex. Left (LVO) and right (RVO) ven- tricular output were assessed using CMR Tools processing software. Echocardiographic measurements of LVO were performed within 24 hours of MR imaging.

\section{Results}

108 newborn infants with median birth weight 1627 (580-4140) grams, gestation 32 (25-42) weeks were studied. Mean (SD) flow volumes in 28 stable infants were LVO 222 (46), RVO 219 (47), SVC 95 (27) and DAo 126 (32) $\mathrm{ml}^{\mathrm{kg}}{ }^{-1} \cdot \mathrm{min}^{-1}$, with flow being higher at lower gestational age. Limits of agreement (LOA) for repeated PC assessment of flow were $\mathrm{LVO} \pm 50.2, \mathrm{RVO} \pm 55.5, \mathrm{SVC} \pm$ 20.9 and DAo $\pm 26.2 \mathrm{ml} \cdot \mathrm{kg}^{-1} \cdot \mathrm{min}^{-1}$. Phase contrast quantification of flow in an external phantom was highly correlated with actual measured flow $\left(\mathrm{r}^{2}=0.995\right)$. Mean (SD) LVO in 75 stable infants by bFFE was 245 (47) ml.kg${ }^{1} . \mathrm{min}^{-1}$, LOA for cine assessment of LVO were \pm 58.3 $\mathrm{ml} . \mathrm{kg}^{-1} \cdot \mathrm{min}^{-1}$. LOA for repeated echocardiographic assessment of LVO were $\pm 108.9 \mathrm{ml} . \mathrm{kg}^{-1} \cdot \mathrm{min}^{-1}$.

\section{Conclusion}

Detailed CMR assessments of cardiac function and systemic perfusion are feasible in newborn infants, and provide more complete data and with greater accuracy than existing echocardiographic methods. 